\title{
Investigation on the ZBG-functionality of phenyl-4-yl-acrylohydroxamic acid derivatives as histone deacetylase inhibitors
}

Loana Musso $^{\mathrm{a}}$, Raffaella Cincinelli ${ }^{\mathrm{a}}$, Valentina Zuco ${ }^{\mathrm{b}}$, Franco Zunino $^{\mathrm{b}}$, Alessandra Nurisso ${ }^{\mathrm{c}}$, Muriel Cuendet $^{\mathrm{c}}$, Giuseppe Giannini ${ }^{\mathrm{d}}$, Loredana Vesci ${ }^{\mathrm{d}}$, Claudio Pisano $^{\mathrm{d}}$, Sabrina Dallavalle ${ }^{\mathrm{a}^{*}}$

${ }^{a}$ Department of Food, Environmental and Nutritional Sciences, University of Milan, via Celoria 2, 20133 Milan, Italy

${ }^{b}$ Fondazione IRCCS Istituto Nazionale Tumori, Via Amadeo 42, 20133 Milan, Italy

'School of pharmaceutical sciences, University of Geneva, University of Lausanne, Quai Ernest-Ansermet 30, 1211

Geneva 11, Switzerland

${ }^{d} R \& D$ Sigma-Tau Industrie Farmaceutiche Riunite S.p.A., Via Pontina Km 30,400, I-00040 Pomezia, Roma, Italy

${ }^{\S}$ Present Address: Biogem SCARL, Via Camporeale, I-83031 Ariano Irpino (AV), Italy.

${ }^{*}$ Corresponding author. Tel. +39-02-50316818; Fax: +39-02-50316801

E-mail address: sabrina.dallavalle@ unimi.it

\begin{abstract}
A series of alternative Zn-binding groups were explored in the design of phenyl-4-ylacrylohydroxamic acid derivatives as histone deacetylase (HDAC) inhibitors. Most of the synthesized compounds were less effective than the parent hydroxamic acid. However, the profile of activity shown by the analogue bearing a hydroxyurea head group, makes this derivative promising for further investigation.
\end{abstract}

Keywords: histone deacetylase (HDAC) inhibitors; Zn-binding group; antiproliferative activity; synthesis.

Over the last 10 years the reversible acetylation of histones and other proteins has emerged as an important regulatory mechanism implicated in cell proliferation and has been identified as a valuable target for anticancer drug design.

Acetylation is executed by histone acetyltransferases and is reversed by histone deacetylases (HDACs). ${ }^{1}$ Eighteen mammalian HDAC enzymes have been identified so far, which can be 
subdivided into two families according to a cofactor $\left(\mathrm{Zn}^{2+}\right.$ for Classes I, II and IV or $\mathrm{NAD}^{+}$for Class III) for activity. ${ }^{2}$

A number of HDAC inhibitors reached clinical trials, and five of them were approved by FDA: Vorinostat (Zolinza; 2006), Romidepsin (Istodax; 2009) both for use in peripheral T-cell lymphoma (CTCL) with the latter also for use in peripheral T-cell lymphoma (CTCL) (2011). Belinostat (Beleodaq; 2014) and Chidamide (Epidaza; 2015) both for use in CTCL and, more recently, Panobinostat (Farydak; 2015) for use in multiple myeloma. ${ }^{3}$ They all fit in the widely accepted HDAC pharmacophore model for HDAC inhibitors characterized by a cap group, a linker chain and a zinc binding group (ZBG). ${ }^{4}$ Based on molecular modelling studies involving the histone deacetylase-like protein (HDLP), these molecules appear to bind in a pocket of the HDAC active site in such a way that the metal binding moiety (a hydroxamic acid for SAHA, Belinostat and Panobinostat, a thiol derivative for Romidepsin and a benzamide for Chidamide), coordinates the catalytic zinc ion at the end of the pocket. Binding of the $\mathrm{Zn}^{2+}$ ion has proven to be crucial for the activity.

Since the discovery of SAHA, structural studies to identify novel HDAC inhibitors have mainly focused on modifications of the linker or the cap group, while less attention has been paid to the metal binding group.

Hydroxamic acid derivatives represent the most studied and successful class of HDAC inhibitor drug candidates. However, although very powerful, they suffer from poor metabolic stability and a rapid excretion.,6 The different clinical applications of this class of drugs, such as CNS, inflammatory and HIV diseases, require a renewed effort in the search for new ZBG.

Several efforts have been made to replace the hydroxamic acid with alternative chemical moieties that could also further improve the isoform selectivity of HDAC inhibitors. ${ }^{7-11}$

As part of a previous research program aimed at studying new HDAC inhibitors, we have developed a series of hydroxamic acid-based compounds, characterized by a cinnamic spacer capped with a substituted phenyl group (1, Figure 1). ${ }^{12}$ Extensive research has been conducted on the derivatization of the cap group, to optimize drug-target interactions. ${ }^{12-14}$

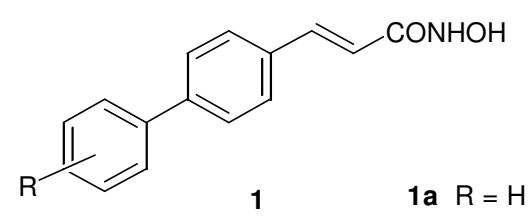

Figure 1. General structure of compounds 1. 
Recently, we have initiated the search for moieties that would retain the zinc-binding properties and enzyme inhibitory activity of the hydroxamic acid group. In this paper we report the attempts made to modify the ZBG-functionality of the 4-vinylbiphenyl scaffold.

A series of analogues incorporating non-hydroxamic groups was designed to probe the potential of various ZBGs. Indeed, very stringent constraints should be satisfied in order to have zinc binding (as with the hydroxamic acid group), and also interactions with amino acid residues of the enzymes to have a strong binding affinity. ${ }^{15}$ The N-hydroxyurea group appears to be an interesting possible replacement for the hydroxamate group commonly found in HDAC inhibitors, because both groups display an identical binding mode. ${ }^{15-17}$ SAHA N-hydroxyurea derivative was found to show antiHDAC activity even though it was much less effective than SAHA. ${ }^{16}$ To investigate the effect of the hydroxyurea group on the 4-vinylbiphenyl scaffold, compound 6 was synthesized starting from acid 2 (weak $\mathrm{Zn}^{2+}$ coordinator), which was tested for its HDAC inhibitory activity as well. The acid was quantitatively converted into the corresponding isocyanate $\mathbf{4}$ by treatment with diphenylphosphorylazide (DPPA) in dry $\mathrm{CH}_{2} \mathrm{Cl}_{2}$. This latter was reacted with hydroxylamine in toluene to give the hydroxyurea $\mathbf{6}$. The same strategy was used to prepare the O-benzyl derivative 7 (Scheme 1).

Isocyanate 4 was also used as an intermediate to prepare semicarbazide $\mathbf{5}$, based on the consideration that a SAHA semicarbazide derivative was found to be active as HDAC inhibitor. ${ }^{16}$ As other derivatives with a hydrazide group showed HDAC inhibitory activity, ${ }^{18}$ we also replaced the hydroxamic acid moiety of reference compound 1a with a hydrazide counterpart. Accordingly, compound 3 was prepared by condensation of acid $\mathbf{2}$ with hydrazine in the presence of $\mathrm{HOBt}$ and EDC (Scheme 1). ${ }^{19}$ 


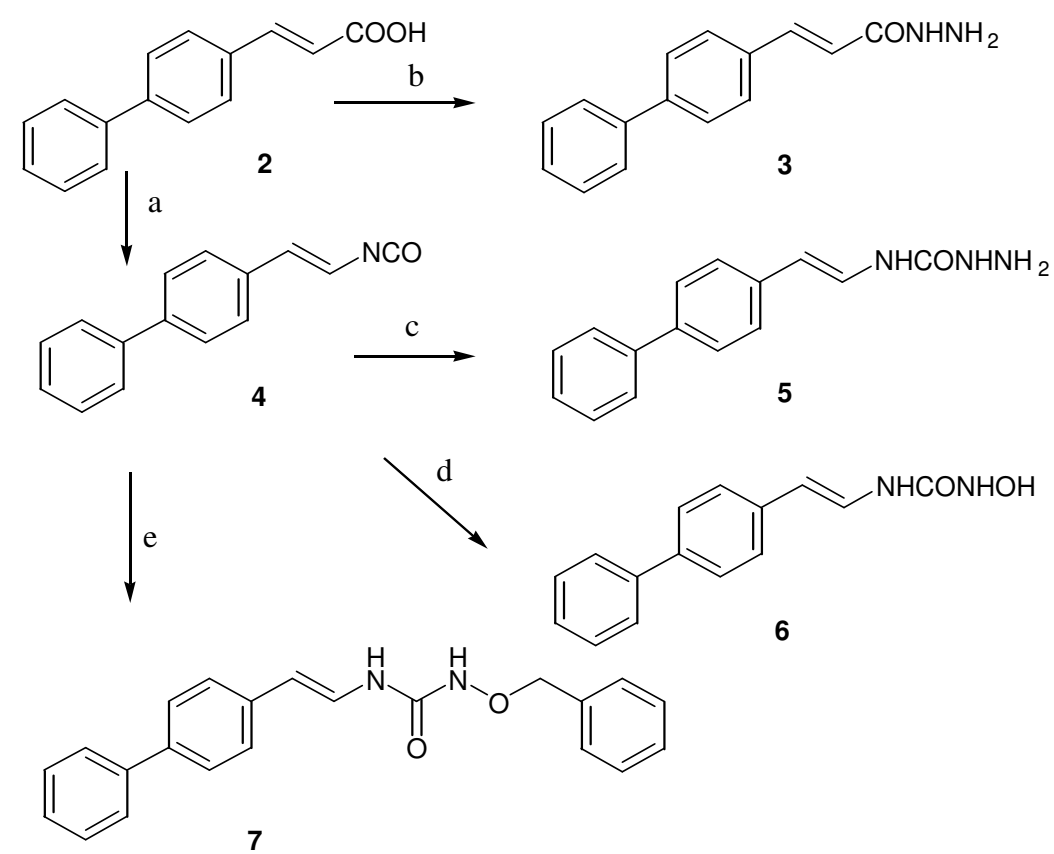

(a) DPPA, TEA, $\mathrm{CH}_{2} \mathrm{Cl}_{2}$, reflux, 7h, 100\%; (b) $\mathrm{HOBT}, \mathrm{EDC}, \mathrm{NH}_{2} \mathrm{NH}_{2} \cdot \mathrm{H}_{2} \mathrm{O}$,

cyclohexene, acetonitrile, $0-10{ }^{\circ} \mathrm{C}, 10 \mathrm{~min}$., $77 \%$; (c) $\mathrm{NH}_{2} \mathrm{NH}_{2} \cdot \mathrm{H}_{2} \mathrm{O}$, toluene, 80 ${ }^{\circ} \mathrm{C}, 1 \mathrm{~h}, 63 \%$; (d) $\mathrm{NH}_{2} \mathrm{OH}$, toluene, reflux, $1 \mathrm{~h}, 53 \%$ (e) O-benzylhydroxylamine, toluene, reflux, $3.5 \mathrm{~h}, 23 \%$.

Scheme 1. Synthesis of compounds 2-7.

Other groups were selected based on the concept that it is possible for them to bind to the zinc ion. Sulfur ligands are well known to bind tightly to $\mathrm{Zn}$ containing enzymes. In particular, HDAC inhibitors with $\alpha$-thioacetate ${ }^{20}$ as well as $\alpha$-thioacetoxyketone moiety in place of the hydroxamic acid showed higher inhibition of the enzyme than SAHA. ${ }^{21,22}$ Based on these results, the synthesis of analogues harbouring an $\alpha$-thioacetoxyketone as a ZBGon the phenyl-4-yl-acryloyl scaffold was performed. Heck condensation between 4-bromobiphenyl 8 and but-3-en-2-one afforded ketone 9 that was brominated with pyrrolidone hydrotribromide to obtain 10. Treatment of this latter with potassium thioacetate gave the desired thioacetoxyketone 11 in good yield (Scheme 2).

We also speculated that another possible ZBG could be the thiocyanate group, which is known to bind the $\mathrm{Zn}$ ion through the nitrogen atom. ${ }^{23}$ Thus, compound $\mathbf{1 4}$ was prepared from 4bromobiphenyl 8, which was coupled with 3,3-diethoxypropene to obtain aldehyde $\mathbf{1 2}$ in $78 \%$ yield. Reduction by $\mathrm{NaBH}_{4}$, followed by treatment with $\mathrm{PBr}_{3}$ afforded the bromide $\mathbf{1 3}$ in $88 \%$ overall yield. Reaction with silica gel-supported potassium thiocyanate ${ }^{24}$ afforded compound $\mathbf{1 4}$ in good yield. (Scheme 2). 
<smiles>CC(=O)/C=C/c1ccc(-c2ccccc2)cc1</smiles><smiles>CC(C)(C)c1ccc(-c2ccc(C=CC=O)cc2)cc1</smiles>

(a) But-3-en-2-one, Palladium acetate, tri(o-tolyl)phosphine, TEA, $100-110^{\circ} \mathrm{C}, 12 \mathrm{~h}, 42 \%$; (b) Pyrrolidone hydrotribromide, THF, rt, 24h, 41\%; (c) potassium thioacetate, DMF, rt, 2.5h, 56\%; (d) 3,3-Diethoxypropene, $\mathrm{Bu}_{4} \mathrm{NOAc}, \mathrm{K}_{2} \mathrm{CO}_{3}, \mathrm{KCl}, \mathrm{Pd}(\mathrm{OAc})_{2}$, DMF, $100^{\circ} \mathrm{C}, 5 \mathrm{~h}, 78 \%$; (e) $\mathrm{NaBH}_{4}, \mathrm{EtOH}, \mathrm{rt}, 30 \mathrm{~min}, 98 \%$; (f) $\mathrm{PBr}_{3}, \mathrm{Et}_{2} \mathrm{O}$, rt, $1 \mathrm{~h}, 90 \%$; (g) potassium thiocyanate- $\mathrm{SiO}_{2}$, hexane, $50^{\circ} \mathrm{C}, 3.5 \mathrm{~h}, 78 \%$.

Scheme 2. Synthesis of compounds 11 and 14.

During the past years, Cohen's group has investigated several new cyclic ketones and lactones as ZBGs for Zn-dependant enzymes. Among them, they proposed some 6-membered cyclic hydroxamic and thiohydroxamic acids. ${ }^{25}$ The purpose to investigate the effect of a 5-membered cyclic hydroxamic acid, which should be the closest structural analogue of hydroxamic acid, prompted us to synthesize compound 17 (Scheme 3). When this work was already in an advanced stage, the same group was reported as a novel ZBGs for HDAC inhibitors. ${ }^{26}$

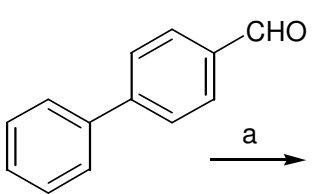

15

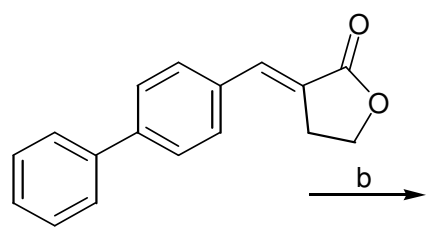

16<smiles>O=C1/C(=C/c2ccc(-c3ccccc3)cc2)CCN1O</smiles>

17

(a) Butyrolactone, NaOMe, toluene, $-10^{\circ} \mathrm{C}$ for $5 \mathrm{~min}$, then rt for $1.5 \mathrm{~h}, 89 \%$; (b) $\mathrm{NH}_{2} \mathrm{OH} . \mathrm{HCl}$, EtONa, reflux, 3.5h, $20 \%$.

Scheme 3. Synthesis of compound 17.

The synthesized compounds were tested for their inhibitory activity towards HDAC2 isoform (Table 1), and for cell growth inhibition against a panel of tumor cell lines of different tissue origin: NB4 (human acute promyelocytic leukemia), H460 (human lung carcinoma), HCT116 (human colon cancer), IGROV-1 and its subline resistant to cisplatinum IGROV-1/Pt1(human ovarian carcinoma) (Table 2). 
Table 1 HDAC2 inhibitory activity of synthesized compounds.

\begin{tabular}{cc}
\hline Cpd & HDAC2 $^{\mathrm{a}}\left(\mathrm{IC}_{50}, \mu \mathrm{M}\right)$ \\
\hline SAHA & $0.15 \pm 0.02$ \\
\hline $\mathbf{1 a}$ & $0.82 \pm 0.14$ \\
$\mathbf{2}$ & $>5$ \\
$\mathbf{3}$ & $>5$ \\
$\mathbf{5}$ & $>5$ \\
$\mathbf{6}$ & $1.05 \pm 0.62$ \\
$\mathbf{7}$ & $>5$ \\
$\mathbf{1 1}$ & $>5$ \\
$\mathbf{1 4}$ & $>5$ \\
$\mathbf{1 7}$ & $>5$ \\
\hline
\end{tabular}

${ }^{\text {a }} \mathrm{HDAC}$ activity was determined using $\mathrm{HDAC} 2$ from HeLa cells as indicated in SI

Table 2 Cell growth inhibition $\left(\mathrm{IC}_{50}, \mu \mathrm{M}\right)$ of synthesized compounds and reference HDAC inhibitor (SAHA) against a panel of tumor cell lines.

\begin{tabular}{lccccc}
\hline cpd & IGROV-1 & IGOV/Pt1 & HCT116 & NB4 & H460 \\
\hline \multicolumn{5}{c}{$\mathrm{IC}_{50}(\mu \mathrm{M})^{\mathrm{a}}$} \\
\hline SAHA & $2.2 \pm 0.3$ & $2.2 \pm 0.2$ & $1.2 \pm 0.1$ & $0.70 \pm 0.03$ & $3.4 \pm 0.8$ \\
$\mathbf{1 a}$ & $3.5 \pm 0.6$ & $4.0 \pm 0.4$ & $1.6 \pm 0.3$ & $0.9 \pm 0.1$ & $5.4 \pm 0.1$ \\
$\mathbf{2}$ & - & - & $>20$ & $>10$ & $>20$ \\
$\mathbf{3}$ & $7.6 \pm 0.2$ & $25.1 \pm 5.9$ & $11.9 \pm 1.2$ & $7.1 \pm 0.7$ & $>20$ \\
$\mathbf{5}$ & $14.5 \pm 0.3$ & $26.7 \pm 0.3$ & $16.4 \pm 3.0$ & $9.8 \pm 0.9$ & $>20$ \\
$\mathbf{6}$ & $3.5 \pm 0.3$ & $6.7 \pm 0.2$ & $4.0 \pm 0.7$ & $1.96 \pm 0.1$ & $9.5 \pm 0.4$ \\
$\mathbf{7}$ & $40 \pm 1$ & $>>50$ & $40 \pm 3$ & $>20$ & $>20$ \\
$\mathbf{1 1}$ & $26.4 \pm 0.8$ & $18.7 \pm 0.6$ & $14.0 \pm 1.5$ & $>20$ & $>20$ \\
$\mathbf{1 4}$ & $3.8 \pm 0.6$ & $58.1 \pm 2.6$ & $12.6 \pm 3.8-$ & $>20$ & $9.4 \pm 1.6$ \\
$\mathbf{1 7}$ & $>>60$ & $>>60$ & $>20$ & $>20$ & $>20$ \\
\hline
\end{tabular}

Most of the synthesized compounds were characterized by a low activity (compared to SAHA) in terms of both HDAC inhibition and cell growth inhibition. In spite of a lack of enzymatic activity, compounds $\mathbf{3}, \mathbf{5}, \mathbf{1 1}$, and $\mathbf{1 4}$ showed a moderate cell growth inhibition, most likely related to the inhibition of multiple targets. In fact, there appears to be a common opinion that inhibitors containing metal binding groups can be prone to widespread off-target enzymatic inhibition, due to non-specific metal binding. ${ }^{27}$

The introduction of an O-benzyl hydroxyurea moiety (compound 7) and of a 5-membered cyclic hydroxamic acid (compound 17) led to a loss of activity Only compound 6, bearing a hydroxyurea as ZBG, exhibited activity comparable to the parent compound 1a, both in HDAC2 and cell growth inhibitions. 
Thus, the profiling of 6 was carried out also against HDAC 1 and HDAC 6 isoforms, using SAHA as a reference compound. The results (HDAC1: compound 6, $\mathrm{IC}_{50} 1.31 \pm 0.21 \mu \mathrm{M}$. SAHA, $\mathrm{IC}_{50}$ $0.12 \pm 0.01 \mu \mathrm{M}$; HDAC6: compound 6, IC $\mathrm{I}_{50} 1.05 \pm 0.09 \mu \mathrm{M}$. SAHA, IC50 $\left.0.07 \pm 0.01 \mu \mathrm{M}\right)$ suggested that the compound was a multi-HDAC inhibitor, its activity against HDAC 1 and 6 being comparable to the activity against HDAC 2 (see SI for details).

A structural rationalization study was conducted in order to understand the main interaction features of compounds 1a and $\mathbf{6}$ with the enzyme. The molecular docking protocol adopted here has been validated in the past through the re-docking of the co-crystallized SAHA within the HDAC2 protein structure. ${ }^{28}$ Both the hydroxamate and N-hydroxyurea groups of compound 1a (ChemPLP score of the best ranked pose: $69.8 ; 100 \%$ convergent docking solutions) and 6 (ChemPLP score of the best ranked pose: $75.4 ; 100 \%$ convergent docking solutions), respectively, were involved in zinc chelation. Polar interactions of these chelating groups with neighbor residues (His146, Tyr308) were also observed. The additional nitrogen atom present in compound $\mathbf{6}$ made a hydrogen bond with Gly154. The zinc binding groups of both molecules were connected to two phenyl rings, the first one stabilized by hydrophobic interactions with Phe105, Phe210, and Leu276, the second one solvent exposed in both cases (Figure 2).

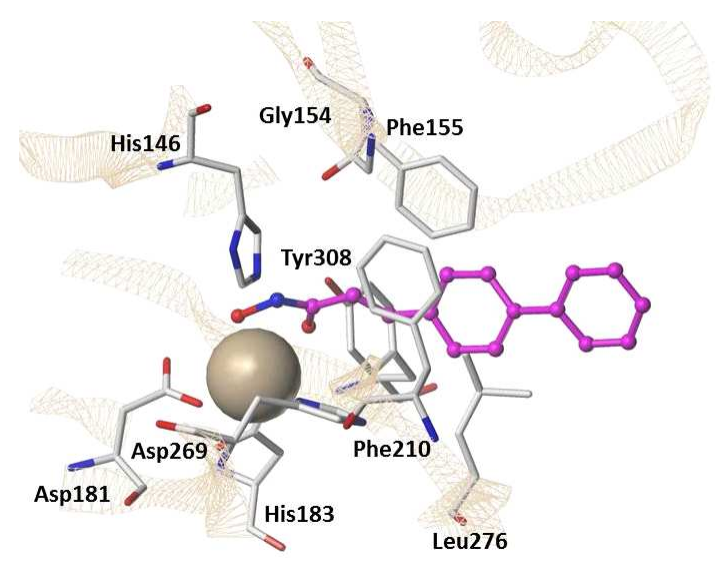

A

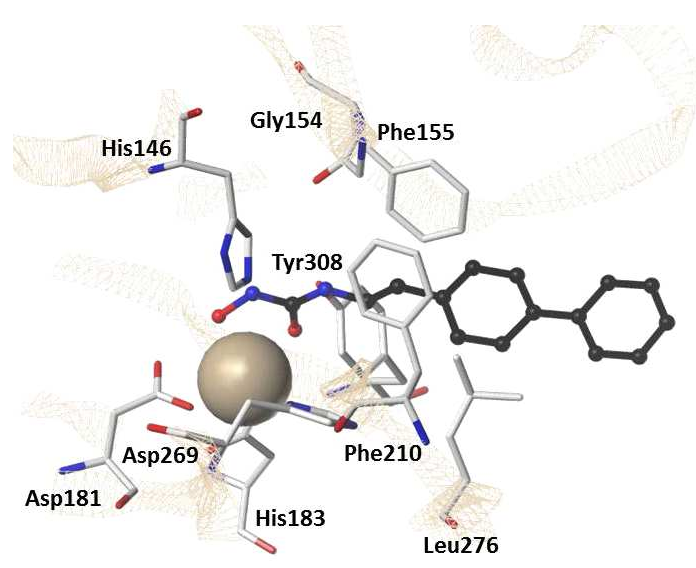

B

Figure 2. HDAC2 in complex with compound 1a (best-ranked pose, purple balls \& sticks, A), and compound 6 (best-ranked pose, black balls \& sticks, B). The protein is reported as gray ribbons. Zinc ion is indicated as a gray ball. Key residues for ligands stabilization are labeled.

In conclusion, we explored alternative ZBGs in the design of phenyl-4-yl-acrylohydroxamic acid derivatives as HDAC inhibitors. Most of the synthesized compounds were less effective than the parent hydroxamic acid 1a. However, the profile of activity shown by compound $\mathbf{6}$, bearing a 
hydroxyurea head group, makes this derivative a promising candidate for further investigation, also taking into account the potential improvement in terms of bioavailability/metabolism of hydroxyurea over hydroxamate. ${ }^{29,30}$

\section{Supplementary data}

Supplementary data associated with this article can be found, in the online version, at

\section{References and notes}

1. Grunstein, M. Nature 1997, 389, 349.

2. Mottamal, M.; Zheng, S.; Huang, T. L.; Wang, G. Molecules 2015, 20, 3898.

3. Falkenberg K. J.; Johnstone R.W. Nat. Rev. Drug Discov. 2014, 13, 673.

4. Paris, M.; Porcelloni, M.; Binaschi, M.; Fattori, D. J. Med. Chem. 2008, 51, 1505.

5. Summers, J. B.; Gunn, B. P.; Mazdiyasni, H.; Goetze, A. M.; Young, P. R.; Bouska, J. B.; Dyer, R. D.; Brooks, D. W.; Carter, G. W. J. Med. Chem. 1987, 30, 2121.

6. Kelly, W. K.; Richon, V. M.; O’Connor, O.; Curley, T.; MacGregor-Curtelli, B.; Tong, W.; Klang, M.; Schwartz, L.; Richardson, S.; Rosa, E.; Drobnjak, M.; Cordon-Cordo, C.; Chiao, J. H.; Rifkind, R.; Marks, P. A.; Scher, H. Clin. Cancer Res. 2003, 9, 3578.

7.Sodji, Q. H.; Patil, V.; Kornacki, J. R.; Mrksich, M.; Oyelere, A. K. J. Med. Chem. 2013, 56, 9969.

8. Ononye, S. N.; VanHeyst, M. D.; Oblak, E. Z.; Zhou, W.; Ammar, M.; Anderson, A. C.; Wright, D. L. ACS Med. Chem. Lett. 2013, 4, 757.

9. Dallavalle, S.; Pisano, C.; Zunino, F. Biochem. Pharmacol. 2012, 84, 756.

10. Madsen, A. S; Kristensen, H.M. E.; Lanz, G.; Olsen C. A. Chem Med Chem 2014, 9, 614.

11. Suzuki, T.; Miyata, N. Curr. Med. Chem. 2005, 12, 2867.

12. Dallavalle, S.; Cincinelli, R.; Nannei, R.; Merlini, L.; Morini, G.; Penco, S.; Pisano, C.; Vesci,

L.; Barbarino, M.; Zuco, V.; De Cesare, M.; Zunino, F. Eur. J. Med. Chem. 2009, 44, 1900.

13. Cincinelli, R.; Musso, L.; Giannini, G.; Zuco, V.; De Cesare, M.; Zunino, F.; Dallavalle, S. Eur. J. Med. Chem. 2014, 79, 251.

14. Giannini, G.; Brunetti, T.; Pezzi, R.; Battistuzzi, G.; Di Marzo, M.; Marzi, M.; Cabri, W.; Vesci, L.; Pisano, C. Bioorg. Med. Chem. Lett. 2009, 19, 2346.

15. Vanommeslaeghe, K.; Loverix, S.; Geerlings, P.; Tourwe', D. Bioorg. Med. Chem. 2005, 13, 6070. 
16. Suzuki, T.; Nagano, Y.; Kouketsu, A.; Matsuura, A.; Maruyama, S.; Kurotaki, M.; Nakagawa, H.; Miyata, N. J. Med. Chem. 2005, 48, 1019.

17. Hanessian, S.; Vinci, V.; Auzzas, L.; Marzi, M.; Giannini, G. Bioorg. Med. Chem. Lett. 2006, 16,4784 .

18. Hou, X.; Du, J.; Liu, R.; Zhou, Y.; Li, M.; Xu, W.; Fang, H. J. Chem. Inf. Model. 2015, 55, 861.

19. Zhang, X.; Breslav, M.; Grimm, J.; Guan, K.; Huang, A.; Liu, F.; Maryanoff, C. A.; Palmer, D.; Patel, M.; Qian, Y.; Shaw, C.; Sorgi, K.; Stefanick, S.; Xu. D. -J. Org. Chem. 2002, 67, 9471.

20. Giannini, G.; Vesci, L.; Battistuzzi, G.; Vignola, D.; Milazzo, F. M.; Berardino Guglielmi M.; Barbarino, M.; Santaniello, M.; Fanto, N.; Mor, M.; Rivara, S.; Pala, D.; Taddei, M.; Pisano, C.; Cabri, W. J. Med. Chem. 2014, 57, 8358.

21. Wash, P. L.; Hoffman, T. Z.; Wiley , B. M.; Bonnefous, C.; Smith, N. D.; Sertic, M: S.; Lawrence, C. M.; Symons, K. T.; Nguyen, P-M.; Lustig, K. D.; Guo, X.; Annable. T.; Noble, S. A.; Hager, J. H.; Hassig, C. A.; Malech, J. W. Bioorg. Med. Chem. Lett. 2008, 18, 6482.

22. Gu, W.; Nusinzon, I.; Smith, R. D. Jr.; Horvath, C. M.; Silverman, R. B. Bioorg. Med. Chem. 2006, 14,3320 .

23. Diaz, A.; Massacesi, M.; Ponticelli, G.; Paschina, G. J. Inorg. Nuclear Chem.1975, 37, 2469... 24. Ando, T.; Clark, J. H.; Cork, D. G.; Fujita, M.; Kimura, T. J. Org. Chem., 1987, 52, 681.

25. Jacobsen, J. A.; Fullagar, J. L.; Miller, M. T.; Cohen, S. M. J. Med. Chem. 2011, 54, 591.

26. Mutule, I.; Borovika, D.; Rozenberga, E.; Romanchikova, N.; Zalubovskis, R.; Shestakova, I.; Trapencieris. P. J. Enz. Inhib. Med. Chem. 2015, 30, 216.

27. Day, J. A.; Cohen, S. M. J. Med. Chem. 2013, 56, 7997.

28. Zwick, V.; Chatzivasileiou, A.-O.; Deschamps, N.; Roussaki, M.; Simoes-Pires, C.; Nurisso, A.; Denis, I.; Blanquart, C.; Martinet, N.; Carrupt, P.-A.; Detsi, A.; Cuendet, M. Bioorg. Med. Chem. Lett. 2014, 24, 5497.

29. Campestre, C.; Agamennone, M.; Tortorella, P.; Preziuso, S.; Biasone, A.; Gavuzzo, E.; Pochetti, G.; Mazza, F.; Hiller, O.; Tschesche, H.; Consalvi, V.; Gallina, C. Bioorg. Med. Chem. Lett. 2006, 16, 20.

30. Stewart, A. O.; Bhatia, P. A.; Martin, J. G.; Summers, J. B.; Rodriques, K. E.; Martin, M. B.; Holms, J. H.; Moore, J. L.; Craig, R. A.; Kolasa, T.; Ratajczyk, J. D.; Mazdiyasni, H.; Kerdesky, F. A. J.; DeNinno, S. L.; Maki, R. G.; Bouska, J. B.; Young, P. R.; Lanni, C.; Bell, R. L.; Carter, G. W.; Brooks, C. D. W. J. Med. Chem. 1997, 40, 1955. 
